\title{
O PAPEL DO TREINAMENTO OSTENSIVO NA AQUISIÇÃO DA LINGUAGEM NATURAL
}

\author{
Juliano do Carmo
}

UFPel

RESUMO: A tese da universalidade da linguagem defendida por aprioristas, como Jerry Fodor (The Language of Thought), e inatistas, como Noam Chomsky (Aspects of the Theory of Syntax), tem sido contestada por diversos filósofos, linguistas e teóricos da Psicologia Cognitiva ao longo das últimas décadas. Aprioristas e inatistas em geral concordam que é necessário, de um ponto de vista explicativo, pressupor a existência de uma linguagem do pensamento ou de categorias inatas universais para explicar o processo de aquisição de uma linguagem natural. Neste trabalho, vou procurar mostrar que a noção de "treinamento ostensivo", enquanto um elemento pré-linguístico para a aquisição de habilidades semânticas e cognitivas, pode oferecer uma resposta satisfatória ao problema da aquisição da linguagem natural, sem a necessidade de pressupor uma linguagem privada do pensamento ou categorias biológicas inatas.

\begin{abstract}
The thesis of the universality of language advocated by apriorists like Jerry Fodor (The Language of Thought), and inatism, as Noam Chomsky (Aspects of the Theory of Syntax), has been challenged by various philosophers, linguists and theorists Cognitive Psychology in the past decades. Apriorists and inatism generally agree that it is necessary, an explanatory point of view, presuppose the existence of a language of thought or innate universal categories in order to explain the process of acquisition of a natural language. In this paper, I will try to show that the notion of "ostensive training", while a pre-linguistic element to the acquisition of semantic and cognitive abilities, can offer a satisfactory answer to the problem of acquisition of natural language, without necessarily to assume a private language of thought or innate biological categories.
\end{abstract}

\section{Diferentes Perspectivas no Processo de Aquisição de Linguagem}

O processo de aquisição da linguagem natural é tema de ampla discussão entre linguistas, filósofos, psicólogos e neurocientistas, sobretudo em virtude da controvérsia a respeito das explicações oferecidas para os processos 
de aquisição das habilidades necessárias para a aprendizagem e o desenvolvimento da linguagem. O fato de que aprendizes em um "ambiente verbal", mesmo sem um treinamento formal, geralmente aprendem a falar e a compreender as expressões da linguagem sem grandes dificuldades tem levado muitos teóricos a pensar que deve haver necessariamente alguma estrutura sintática ou semântica prévia que os permita compreender e utilizar uma linguagem natural. Como veremos, não é necessário pressupor “categorias inatas" ou mesmo uma "linguagem privada do pensamento" para explicar o processo de aquisição da linguagem natural. Além disso, cabe ressaltar, todas as alternativas atualmente disponíveis para explicar este processo funcionam, na melhor das hipóteses, como inferências à melhor explicação ${ }^{1}$.

O argumento inatista (ou nativista) de Noam Chomsky, exposto em Aspects of the Theory of Syntax de 1965, visa demonstrar que o aprendizado da linguagem não pode depender de um mero input linguístico, pois o input não seria suficientemente capaz de desenvolver no aprendiz as ferramentas necessárias para o processamento potencialmente infinito de sentenças de uma linguagem natural. A estratégia de Chomsky é defender que existem certas categorias gramaticais biológicas inatas e universais (uma vez que estariam supostamente presentes em todas as linguagens naturais conhecidas), tais como nomes e verbos, que possibilitam o desenvolvimento completo da linguagem nos aprendizes. Além disso, os aprendizes possuem uma espécie de disposição natural (instintiva) para associar nomes a verbos e assim formar sentenças completas e significativas. Como é bem conhecido, o sucesso da estratégia de Chomsky depende da pressuposição de uma Gramática Universal (categorias biológicas inatas). Contudo, a ideia de uma Gramática Universal

\footnotetext{
1 Eu gostaria de endereçar um especial agradecimento a todos aqueles com os quais tive a oportunidade de discutir (em diversos eventos) algumas das ideias que desenvolvo neste trabalho. Aproveito a oportunidade para agradecer também aos meus queridos colegas Carlos Miraglia e Flávia Carvalho Chagas, pelos excelentes comentários, críticas e sugestões.
} 


\section{Dossiê Naturalismo, Dissertatio - Volume Suplementar 02 | UFPel [2015]}

tem sido recusada fortemente pelos teóricos da Psicologia Cognitiva, sobretudo no que diz respeito as supostas categorias básicas (nomes e verbos), pois, de um ponto de vista biológico e evolutivo, não são claros os motivos pelos quais justamente tais categorias tenham sido selecionadas. O inatismo deveria poder explicar como a "faculdade da linguagem", contendo representações inatas da Gramática Universal, surgiu na mente humana². Até o momento, contudo, não existe consenso sobre como o conhecimento da Gramática Universal (ou de suas categorias) possa ter evoluído em virtude de qualquer elemento adaptativo em nossos ancestrais, já que a habilidade linguística não parece oferecer nenhuma vantagem reprodutiva ${ }^{3}$. Ao invés de pressupor mecanismos inatos específicos para o processamento da linguagem (de uma perspectiva intelectualista), talvez fosse o caso de pressupor que os aprendizes de uma linguagem natural utilizem princípios cognitivos e de aprendizagem em geral. Além disso, o inatismo de Chomsky pressupõe um mecanismo de processamento da linguagem que é excessivamente precoce para os aprendizes, pois pressupõe nos aprendizes as habilidades já completamente desenvolvidas nos usuários competentes da linguagem.

A tese apriorista de Jerry Fodor, por outro lado, exposta em The Language of Thought (1975), está baseada na ideia de que não é possível explicar o processo de aprendizado de uma linguagem natural sem a pressuposição de uma "linguagem privada do pensamento". Fodor defende que para aprender uma linguagem natural os seres humanos precisam ter acesso a representações de certas proposições conceituais, ou seja, é preciso estar apto a manipular certos conceitos ${ }^{4}$. As linguagens naturais são públicas e controladas por critérios igualmente públicos. Contudo, no momento de aquisição de uma

2 Ver: COWIE, F. Innateness and Language. Stanford Enciclopedia of Philosophy, 2008.

3 Ver: LEWONTIN, R. The Evolution of Cognition: Questions we will Never Answer, In R. Sternberg and D. Scarborough (eds.). An Invitation to Cognitive Science. Cambridge: MIT Press, 1998.

${ }^{4}$ Ver: FODOR, J. The Language of Thought. New York: Thomas Y. Crowell Company, 1975. 
linguagem natural os seres humanos não possuem acesso a uma linguagem natural. Portanto, defende Fodor, os conceitos necessários para a aprendizagem ocorrer não podem ser controlados por critérios públicos e, assim, a manipulação prévia de certos conceitos deve ser controlada por regularidades que não são públicas. A estratégia de Fodor (acerca da necessidade explicativa da suposta linguagem privada do pensamento) só parece funcionar na medida em que o modelo computacional de linguagem for verdadeiro e este parece ser um preço excessivamente alto a se pagar por uma explicação do processo de aquisição de linguagem. Além disso, o intelectualismo de Fodor parece pressupor que falar uma língua (como uma ação inteligente) é uma ação necessariamente precedida ou dirigida por uma operação teórica prévia, como a ação intelectual de considerar uma proposição reguladora. Se cada ação inteligente pressupõe uma operação teórica prévia, então parece realmente difícil evitar o regresso de operações teóricas ${ }^{5}$.

O behaviorismo de Skinner, cujas bases encontramos em The Verbal Behavior (1957), tem sido a perspectiva rival mais importante tanto do inatismo como do apriorismo, uma vez que procura explicar o processo de aquisição de linguagem através de eventos empíricos, reais e publicamente observáveis. A ideia básica é a de que a aquisição e o desenvolvimento de uma linguagem natural ocorrem por meio da exposição do aprendiz às influências do ambiente verbal dos usuários competentes da linguagem. $\mathrm{Na}$ medida em que não existem habilidades inatas, é o ambiente verbal que possibilita a associação das palavras com seus significados ${ }^{6}$. Um ambiente verbal é o produto da troca

\footnotetext{
${ }^{5}$ RYLE, G. The Concept of Mind. New York: Routledge, 1949. p. 31.

${ }^{6} \mathrm{O}$ behaviorismo de Skinner procura explicar a aquisição da linguagem em termos da história regressa do sujeito, das circunstâncias atuais e nada mais. De acordo com Stephen Winokur, a ideia é mostrar, a partir de uma análise comportamental da fala, que a aquisição da linguagem está vinculada a diversas variáveis das quais o comportamento verbal é uma função. A psicologia de Skinner, baseada na noção de estímulo-resposta, entende que o comportamento deve ser o ponto central da investigação. Os movimentos produzidos pelos músculos dos animais é que devem ser explicados, ao invés das ideias, significados, desejos, intenções, expectativas, ou qualquer tipo de mecanismos psicológicos hipotéticos.
} 


\section{Dossiê Naturalismo, Dissertatio - Volume Suplementar 02 | UFPel [2015]}

constante entre usuários competentes da linguagem ${ }^{7}$. A estratégia behaviorista consiste em defender que os proferimentos corretos de um aprendiz são positivamente reforçados quando este compreende o valor comunicativo das palavras e sentenças. A linguagem é completamente adquirida através de um condicionamento operante onde os aprendizes percebem certas regularidades no ambiente verbal através de comportamentos verbais positivamente reforçados.

As variáveis das quais o comportamento é uma função são buscadas em eventos empíricos, reais e publicamente observáveis. São observados os estados presentes e passados do organismo (privação), sua constituição genética (um humano ou um chimpanzé podem adquirir um comportamento verbal, mas um pombo não pode), e os estados presentes e passados do ambiente (estímulos); e todas elas são coisas reais, físicas e intersubjetivamente observáveis. As covariações das mudanças nestas variáveis empíricas e as mudanças no comportamento podem ser descritas. As descrições das relações funcionais entre as variáveis empíricas constituem o tipo de consideração causal que estamos interessados ${ }^{8}$.

O que torna as versões clássicas do behaviorismo pouco atrativas, contudo, para combater o inatismo e o apriorismo é a suposta dificuldade de explicar o modo como os sujeitos se tornam autônomos em relação ao condicionamento. Skinner também reconhece que o problema de determinar como o ambiente verbal pode ter surgido de uma fonte não-verbal é alvo de

A ideia, em outras palavras, é salientar que o comportamento verbal é também um tipo de comportamento (não muito diferente do comportamento não-verbal). Segundo Winokur, fazer um ruído com a boca (falar, por exemplo) é um comportamento do mesmo modo que andar de bicicleta também o é. Ver: WINOKUR, S. A primer of verbal behavior: an operant view. Englewood Cliffs: Prentice-Hall, 1976. 1-3. Fodor realiza duras críticas a este modelo de pensamento, sobretudo no que diz respeito a noção de "estímulo proximal" enquanto uma representação proximal do "estímulo distal". Na medida em que não existe uma representação interna sem uma linguagem interna, Fodor crê que o behaviorismo não é uma via razoável para explicar o processo de aquisição da linguagem natural. Ver: FODOR, J. The Language of Thought. New York: Thomas Y. Crowell Company, 1975, pp. 55-65.

${ }^{7}$ SKINNER, B. F. Verbal Behavior. New York: Appleton-Century-Crofts, 1957. p. 461.

${ }^{8}$ WINOKUR, S. A primer of verbal behavior: an operant view. Englewood Cliffs: Prentice-Hall, 1976. 1-3. 
múltiplas especulações e que provavelmente as respostas oferecidas a este problema não passam de inferências à melhor explicação? ${ }^{9}$. Além disso, as explicações apresentadas para realizar essa passagem na maioria das vezes parecem excessivamente artificiais. Ainda assim, tais dificuldades não inviabilizam por completo uma posição anti-intelectualista sobre o processo de aquisição da linguagem natural, mas exige do teórico, como veremos, uma explicação razoável acerca do processo como um todo.

Os estudos sobre os processos encefálicos presentes na aquisição da linguagem têm realizado avanços consideráveis no que diz respeito à descrição das áreas envolvidas ou ativadas quando adquirimos, compreendemos e utilizamos uma linguagem ${ }^{10}$. Os neurocientistas em geral concordam com a tese de que existe uma capacidade inata do cérebro para a aquisição da linguagem. A plasticidade neural ${ }^{11}$, como um elemento anti-intelectualista, tem sido requerida como o ingrediente indispensável para a aquisição de uma linguagem e também para a moldagem da maioria de nossos comportamentos adquiridos, mas ainda não existem estudos empíricos que mostrem que a plasticidade neural seja um elemento necessário e suficiente para explicar a normatividade semântica, por exemplo. Isto é, apesar da ciência procurar

\footnotetext{
${ }^{9}$ SKINNER, B. F. Verbal Behavior. New York: Appleton-Century-Crofts, 1957. p. 461-5.

10 As Neurociências procuram explicar a suposta universalidade da linguagem em virtude do desenvolvimento de regiões específicas no cérebro para o processamento da linguagem (em especial as áreas de Broca e de Wernicke). Contudo, ainda que a maior parte dos estudos e descobertas realizadas pela neurociência seja oriunda de estudos sobre a perda parcial ou completa das habilidades linguísticas (afasia) em função de lesões encefálicas, são escassos os estudos sobre o processo de aquisição de uma primeira linguagem natural. Recentemente, Patrícia Kuhl argumentou a favor da universalidade da linguagem nos seres humanos mostrando, através da magnetoencefalografia, que as crianças aprendem uma linguagem natural pela exposição à fala de um modo diferente daquele encontrado nos demais animais, mas também ressaltou a importância da interação social sobre o aprendizado da linguagem. Os resultados do neuroimageamento e da estimulação encefálica em geral parecem consistentes com as áreas mapeadas para o processamento da linguagem (inferidas a partir das afasias), no entanto, ao que tudo indica, a aquisição e o processamento da linguagem envolve muito mais do que uma simples relação entre as áreas de Broca e de Wernicke. Ver: KUHL, P.K. Learning and Representation in Speech and Language. Current Opinion in Neurobiology, 4: 812-822, 1994.

11 Ver: BEAR, M.; CONNORS, B.; PARADISO, M. Neurociências: Desvendando o Sistema Nervoso. $3^{\circ}$ Edição. Porto Alegre: Artmed, 2010.
} 


\section{Dossiê Naturalismo, Dissertatio - Volume Suplementar 02 | UFPel [2015]}

oferecer uma descrição detalhada dos processos cerebrais envolvidos na aquisição das regras de uma linguagem, ela supostamente não consegue oferecer uma explicação adequada sobre o que nos obriga ou constrange a utilizar ou aplicar tais regras do mesmo modo como as adquirimos nas mais diferentes situações ou jogos de linguagem ${ }^{12}$ (inclusive em situações em que nunca fomos expostos previamente $\left.{ }^{13}\right)$.

$\mathrm{O}$ argumento que desenvolverei a seguir pressupõe a ideia de que uma linguagem natural exige diferentes habilidades de seus usuários e que tais habilidades ${ }^{14}$ não são inatas ou a priori, mas, sim, completamente adquiridas. Apesar de estar disposto a concordar com a hipótese das Neurociências de que deve existir uma "capacidade" cerebral inata para a aquisição da linguagem, como uma espécie de condição necessária, vou argumentar que ela definitivamente não é uma condição suficiente, pois diversas "habilidades" precisam ser adquiridas para que a aprendizagem possa ocorrer.

\section{Naturalismo e Normatividade no Processo de Aquisição da Linguagem Natural}

O modo habitual de explicar o processo de aquisição da linguagem natural é tomar como ponto de partida o "ensino ostensivo" de expressões da linguagem. A “ostensão” é tradicionalmente considerada como um movimento

${ }^{12} \mathrm{~A}$ ideia geral é a de que a investigação sobre o processo de aquisição da linguagem é em parte empírica e em parte filosófica. Ver: HORWICH, P. Naturalism, Deflationism and the Relative Priority of Language and Metaphysics. In: Price, H. Expressivism, Pragmatism and Representationalism. New York: Cambridge University Press, 2013; e ENGELLAND, C. Ostension: Word Learning and the Embodied Mind. Massachusetts: MIT, 2015.

13 Refiro-me aqui ao argumento cético de Kripke exposto em "Wittgenstein on Rules and Private Language".

14 É importante notar que não estou identificando "capacidades" com "habilidades". A principal diferença entre capacidades e habilidades é justamente o fato de que em geral tomamos uma habilidade como algo que é aprendido ao longo da vida, enquanto uma capacidade é considerada como algo com a qual nascemos e que podemos desenvolver. Sendo assim, direi que a compreensão, por exemplo, é uma habilidade (assim como correr e saltar), enquanto a plasticidade neural é uma capacidade (assim como a flexibilidade e a agilidade motoras). 
corporal que supostamente manifesta nossa intencionalidade em relação às coisas ou eventos no mundo. Se gestos e expressões faciais são capazes de revelar estados intencionais, então realmente a ostensão parece ser extremamente importante para o processo de aquisição de linguagem, pois pode fornecer ao aprendiz um modo "pré-linguístico" de compreender palavras e sentenças de uma linguagem natural ${ }^{15}$. É claro que embora a ostensão seja um dos elementos importantes para a aquisição da linguagem, ela certamente não é o único. Os aprendizes devem possuir uma percepção sensorial do mundo e também dos tipos de coisas que devem ser encontradas através dela. Como ressalta Engelland ${ }^{16}$, uma linguagem natural não exige de seus usuários apenas uma semântica, mas também uma sintaxe, e a sintaxe parece exigir muito mais do que os gestos ostensivos. Além disso, os aprendizes precisam de diversas habilidades e capacidades, tais como a articulação de palavras em discurso significativo, memória e motivações. Logo, a ostensão é certamente uma condição necessária, mas não suficiente, para a aquisição da linguagem.

O papel da ostensão no processo de aquisição da linguagem, contudo, nem sempre é claro na literatura especializada. Dependendo da perspectiva teórica adotada, a ostensão pode ser considerada como o elemento primário ou secundário no processo de aprendizagem. Inatistas e aprioristas costumam considerar a ostensão como secundária em relação às habilidades e categorias inatas ou à suposta "linguagem do pensamento" para o desenvolvimento da linguagem. O behaviorismo clássico e as teorias

\footnotetext{
${ }^{15}$ A ostensão tem sido tema de ampla discussão (ao menos desde Platão) na História da Filosofia e contemporaneamente tem figurado como ingrediente essencial nos debates sobre Filosofia da Linguagem e da Mente. Em linhas gerais, busca-se compreender se as intenções podem ser apenas manifestadas (ou expressas) ou se também podem ser também inferidas; se é possível compreender adequadamente ou inequivocamente um "gesto ostensivo".

${ }^{16}$ ENGELLAND, C. Ostension: Word Learning and the Embodied Mind. Massachusetts: MIT, 2015. p. 11.
} 


\section{Dossiê Naturalismo, Dissertatio - Volume Suplementar 02 | UFPel [2015]}

denotacionais do significado em geral consideram a ostensão como primária para a aquisição ou aprendizagem da linguagem. $\mathrm{Na}$ perspectiva antiintelectualista que estou disposto a sustentar a ostensão é primária no processo de aquisição das habilidades necessárias para a aquisição da linguagem e secundária para o desenvolvimento do aprendizado da linguagem.

O que quero ressaltar aqui é a diferença entre o que tem sido chamado de um "treinamento ostensivo"17 e o que em geral se concebe como uma “definição ostensiva”. Essa distinção foi oferecida por Wittgenstein explicitamente nas Investigações Filosóficas (1953), em especial nas passagens reservadas para recusar a visão agostiniana da linguagem. Recentemente, no entanto, Meredith Williams (Johns Hopkins University) resgatou essa distinção, sobretudo em Blind Obedience (2014), ampliando a discussão sobre o processo de aquisição primitiva de linguagem e sua interface com as teorias representacionais do significado e também com as Neurociências.

A “definição ostensiva" foi tema de ampla discussão filosófica no século XX, sobretudo nos trabalhos de Wittgenstein, Quine e Davidson. Basta notar que o primeiro parágrafo das Investigações Filosóficas (1953) de Wittgenstein coloca em questão justamente o papel da "definição ostensiva" no processo de aquisição de linguagem (contra a visão denotacional do significado). Quine impôs sérias críticas à noção de definição ostensiva, sobretudo no que diz respeito ao problema da ambiguidade do "gesto ostensivo", o qual possui relações explícitas com o problema da "indeterminação da tradução" e da “inescrutabilidade da referência”. Davidson buscou resolver o problema da "definição ostensiva" através do processo de "triangulação" (o processo triangular de interação entre dois sujeitos e a interação de cada sujeito com um conjunto comum de objetos no mundo). Para os nossos propósitos, o

\footnotetext{
${ }_{17}^{17}$ WILLIAMS, M. Blind Obedience. New York: Routledge, 2014. p. 80.
} 
problema central da "definição ostensiva" é justamente considerá-la como o elemento primário no processo de aquisição da linguagem.

$\mathrm{Na}$ medida em que o behaviorista clássico defende uma perspectiva não-cognitivista ou não-intelectualista, ele pressupõe que nada além do gesto ostensivo é necessário para a aquisição das primeiras palavras de uma linguagem natural. Creio que o behaviorista está correto ao defender que a ostensão é primária, pois assume que nada além do treinamento é necessário para introduzir um aprendiz no complexo universo da linguagem e nenhuma operação inteligente no que diz respeito ao processo de aquisição da linguagem ${ }^{18}$ seria explicada em termos de operações teóricas prévias. Por outro lado, penso que o behaviorista está equivocado, contudo, na medida em que não realiza a distinção entre "treinamento ostensivo" e "definição ostensiva". Neste sentido, o behaviorismo conduz a uma imagem equivocada da "situação de aprendizagem", pois pressupõe que o aprendiz possui as mesmas habilidades já plenamente desenvolvidas no usuário competente da linguagem.

De modo análogo, as teorias denotacionais do significado costumam defender a tese de que o objeto denotado por uma palavra fixa o significado dessa palavra ao fornecer o padrão para a aplicação correta do termo a outros objetos da mesma classe e em outros contextos. Neste sentido, a teoria denotacional está intimamente associada àquilo que ficou conhecida como a

\footnotetext{
${ }^{18}$ Segundo Ryle, se a ocorrência de qualquer operação inteligente exige necessariamente a ocorrência de uma operação teórica anterior e que esta seja executada de forma inteligente, então haveria uma impossibilidade lógica para qualquer um que nunca tenha entrado neste círculo, e, assim, a aquisição de uma primeira linguagem natural seria impossível. Se utilizar uma linguagem natural é uma ação inteligente, então deve-se presumir que em algum momento a aquisição dessa linguagem não foi 0 resultado de uma operação teórica prévia. 0 objetivo de Ryle é mostrar que certas aplicações de regras, princípios ou normas não exigem necessariamente uma consulta prévia dessas regras, princípios ou normas. Para Ryle, tanto o idealismo como o reducionismo são respostas a uma pergunta ilegítima. Tanto a "redução" do mundo material a processos e estados mentais, como a redução dos estados mentais a processos físicos pressupõem a legitimidade da disjunção exclusiva: ou bem existem mentes ou bem existem corpos (porém, não ambos). É perfeitamente correto dizer com certo ajuste lógico que existem mentes e dizer, em outro ajuste lógico, que existem corpos. Tais expressões não indicam dois tipos de existência diferentes.
} 


\section{Dossiê Naturalismo, Dissertatio - Volume Suplementar 02 | UFPel [2015]}

"visão agostiniana da linguagem", a qual defende que os adultos nomeiam os objetos individuais quando apontam para eles no ambiente imediato do aprendiz. O aprendiz, como um resultado da ostensão, associa o nome proferido pelo adulto com o objeto denotado. Após realizar a associação o aprendiz usa este nome para qualquer objeto que pertença a mesma classe do objeto originalmente nomeado. Ocorre que não é óbvio que o mero ato de denotar seja suficientemente capaz de causar a associação desejada na mente do aprendiz e que este subsequentemente realize as generalizações em relação aos mesmos objetos como o faz um usuário competente da linguagem.

O intelectualista afirma que a relação estabelecida entre a palavra e o objeto não é de simples associação, mas sim de uma "definição ostensiva"19. Ocorre que a própria efetividade da definição ostensiva depende da habilidade cognitiva do aprendiz em compreender que o objeto batizado pelo usuário competente da linguagem é o exemplar que funciona como o padrão para a aplicação correta do termo proferido. O erro da teoria denotacional consiste em não perceber que a situação de aprendizagem não é igualitária entre usuários competentes da linguagem e aprendizes. $\mathrm{Na}$ verdade, como veremos, a situação de aprendizagem é fraturada em dois domínios distintos, embora complementares: o domínio cognitivamente empobrecido do aprendiz e o domínio cognitivamente enriquecido do usuário competente da linguagem ${ }^{20}$.

O erro de tratar a definição ostensiva como o veículo para fixar significados consiste em confundir a definição ostensiva com o treinamento ostensivo. $\mathrm{O}$ treinamento ostensivo é usado com o aprendiz iniciante. Uma vez que o treinamento ostensivo pode ser caracterizado como próximo do condicionamento estímulo-resposta, exemplos deste treinamento podem ser descritos de modo relativamente isolado de qualquer pano de fundo, convenção social ou costume. Esse treinamento resulta em um modo de

19 WILLIAMS, M. Blind Obedience. New York: Routledge, 2014. p. 81.

${ }^{20}$ Idem, p. 19. 
“categorizar" que não é uma questão de nomear e que não pressupõe o pano de fundo e a competência conceitual por parte do aprendiz $(. . .)^{21}$.

Segundo Meredith Williams, a "situação de aprendizagem” é também o elemento fundamental para explicar o problema da normatividade, isto é, o problema de conciliar a determinação causal do treinamento ostensivo com a determinação lógica ou normativa para a aplicação das regras ou normas adquiridas $^{22}$. Algo que o behaviorismo sozinho não consegue explicar. A ideia geral é a de que antes de adquirir uma linguagem natural o aprendiz precisa adquirir as habilidades necessárias para compreender uma linguagem ${ }^{23}$. As habilidades são transmitidas de modo não-cognitivo, isto é, através de exemplos, expressões de aprovação, expressões de reprovação, expressões de encorajamento, etc ${ }^{24}$. Um usuário competente da linguagem é aquele que possui as habilidades semânticas e cognitivas necessárias para a manipulação de conceitos. Como diz Wittgenstein nas Investigações Filosóficas, quem não possui tais habilidades deve ser ensinado através de "exemplos" e "exercícios", através de um "treinamento ostensivo".

Eu lhe mostrarei nesta lição cores iguais, comprimentos iguais, figuras iguais, mandarei que as encontre, as construa, etc. Eu o instruirei para que, dada uma ordem, continue "uniformemente" faixas decorativas. - E o mesmo no que diz respeito a continuar progressões. Eu o faço para ele e ele

\footnotetext{
21 ldem, p. 81.

$22 \mathrm{lbdem}, \mathrm{pp} .80-83$.

${ }^{23}$ WITTGENSTEIN, L. Philosophical Investigations. New York: Blackwell, 2001. §86.

${ }^{24}$ Segundo Williams, Wittgenstein identifica três estágios para a aquisição de uma linguagem natural: 0 primeiro é o "estágio da configuração", onde o aprendiz é submetido a uma série de exemplos acerca do que é "fazer a mesma coisa" (seguir uma regra ou uma progressão aritmética, por exemplo); o segundo é o "estágio do domínio das técnicas ou práticas" e o terceiro é o "estágio da certeza". Qualquer uso da linguagem exige o exercício de técnicas para seguir de um mesmo modo e um sentido mínimo compartilhado do que é óbvio e daquilo que é isento de dúvidas. Compreender uma linguagem, tomando a compreensão como uma habilidade adquirida, é estar apto a reconhecer o comportamento verbal de uma comunidade e estar disposto a seguir suas regras (mesmo que cegamente). Ver: WILLIAMS, M. Blind Obedience. New York: Oxford University Press, 2014.
} 


\section{Dossiê Naturalismo, Dissertatio - Volume Suplementar 02 | UFPel [2015]}

repete o que eu faço, e eu o influencio através de expressões de aprovação, reprovação, expectativa, encorajamento. Deixoo fazer, ou o impeço, etc. ${ }^{25}$

O ensino através da exemplificação e da repetição por meio de exercícios, a influência através de expressões de aprovação e reprovação, através de expressões de expectativa e de encorajamento, o deixar continuar ou o impedir são traços característicos do "treinamento ostensivo" para a aquisição das habilidades necessárias para o aprendizado da linguagem. O "treinamento ostensivo" não implica necessariamente em operações teóricas prévias nem mesmo no conhecimento de proposições verdadeiras sobre como falar uma língua. $\mathrm{O}$ treinamento ostensivo de um ponto de vista não-intelectualista tem por objetivo transmitir uma habilidade ainda não desenvolvida: a habilidade de compreender e manipular conceitos.

O aprendiz não pode pensar apropriadamente por não possuir os requisitos conceituais básicos, mas também por que é apenas através da observação dos exemplos particulares apresentados pelo instrutor que faz com que o aprendiz adquira o sentido do que é "seguir de um mesmo modo" (nos termos de Meredith Williams, "sameness judgements"). O aprendiz adquire as "ferramentas" para agir e julgar através de "exemplos, práticas e técnicas" para participar de jogos de linguagem. Wittgenstein defendeu que o treinamento no uso de regras requer um pano de fundo (um cenário) do mesmo modo que o treinamento para a prática do nomear (só está apto a compreender uma definição ostensiva quem está apto a perguntar pelo nome das coisas ${ }^{26}$ ). Deve existir um pano de fundo dentro do qual o treinamento é efetivado e o gesto ostensivo "assim por diante” é transmitido.

O treinamento ostensivo explora a causalidade baseada em nossas

25 WITTGENSTEIN, L. Philosophical Investigations. New York: Blackwell, 2001, §208.

${ }^{26}$ WITTGENSTEIN, L. Philosophical Investigations. New York: Blackwell, 2001, §30. 
sensibilidades perceptuais em relação a certos objetos e propriedades no mundo, enquanto o "treinamento em práticas normativas" 27 explora a maleabilidade de nosso comportamento e nossa capacidade de oferecer respostas à sua validação. A maleabilidade em nosso comportamento é sustentada pela plasticidade neural, isto é, através da capacidade de nossos cérebros de desenvolver novas conexões sinápticas entre os neurônios a partir da experiência e do comportamento do indivíduo e a partir de determinados estímulos. É claro que nenhuma dessas propensões causais diz respeito a estrutura normativa da linguagem, a qual é governada por padrões de correção, e não por leis causais. As disposições naturais para adquirir certas regularidades básicas de uso $^{28}$ são exploradas ao iniciar o aprendiz nas regularidades normativas dos costumes ou práticas. Diferentemente das posições intelectualistas, na aquisição primitiva da linguagem não existem conceitos para o aprendiz, nem mesmo pano de fundo gramatical ou ambiente articulado. As explicações são transmitidas através de exemplos, encorajamento e desencorajamento para as quais cegamente o aprendiz busca se conformar. Uma vez que nenhuma expressão é explicada por ela mesma, não existe círculo lógico para as explicações que são dadas ao aprendiz.

É apenas através do domínio do usuário competente da linguagem que as palavras e ações do aprendiz tornam-se corretas ou incorretas (contam como reportes genuínos ou não). A situação de aprendizagem pressupõe, por um lado, a divisão de trabalho cognitivo e normativo entre as ações e juízos do aprendiz e, por outro lado, o pano de fundo contra o qual a identidade das ações é fixada e as correções podem ser realizadas ${ }^{29}$. É igualmente importante notar que a situação de aprendizagem é a situação inicial na qual o aprendiz

${ }^{27}$ WILLIAMS, M. Normative Naturalism. International Journal of Philosophical Studies. № 18 (3): pp. 355375, 2011.

28 Ver: HORWICH, P. Meaning. Oxford: Oxford University Press, 1996.

${ }^{29}$ WILLIAMS, M. Blind Obedience. New York: Oxford University Press, 2014. p. 80. 


\section{Dossiê Naturalismo, Dissertatio - Volume Suplementar 02 | UFPel [2015]}

deve realizar "juízos" e estar engajado no "raciocínio" antes de estar apto a fazê-lo.

Os aprendizes são "calibrados" a julgar em conformidade com a comunidade, de modo que posteriormente eles se tornam capazes de pensar e agir independentemente da comunidade. O aprendiz se torna autônomo na medida em que aceita os padrões sancionados pela comunidade ${ }^{30}$. Neste sentido específico é que compreendemos a importância do treinamento ostensivo e a transmissão de "juízos de semelhança normativa": a aceitação dos padrões da comunidade é cega e inevitável, pois não existem outras alternativas disponíveis. Uma maneira de elucidar o estágio de calibração é através da analogia de Wittgenstein sobre o metro-padrão. Existem três características fundamentais do "metro-padrão" que Wittgenstein chama a atenção:

(1) É o uso de um dispositivo (ou seu "propósito") que faz com que ele seja amplamente reconhecido como um metro-padrão;

(2) Existem determinadas "propriedades materiais" que são necessárias para que algum objeto funcione como uma barra de um metro (sua rigidez e sua capacidade de ser gravada com as escalas, por exemplo);

(3) São necessárias as "escalas de medidas" (o centímetro, o milímetro e a marca de um metro gravadas no corpo da barra $)^{31}$;

Nenhuma das propriedades materiais da barra de um metro pode ser considerada como inerentemente representacional ou normativa, já que qualquer coisa utilizada como um metro deve ter propriedades materiais apropriadas para desempenhar esse papel. A barra de um metro define um

30 WILLIAMS, M. Normative Naturalism. International Journal of Philosophical Studies. № 18 (3): pp. 355375, 2011.

31 WITTGENSTEIN, L. Philosophical Investigations. New York: Blackwell, 2001, §§39-50. 
padrão de medida (um sistema convencional de medidas) em virtude de ser utilizada para esse propósito. O fato de que a barra de metal possa ser utilizada para esse propósito é uma função de sua rigidez física e de atribuirmos essa função à barra. Pode acontecer, contudo, que o material utilizado para construir a barra de um metro nunca seja utilizado para esse propósito, isto é, o metal por si mesmo não mede coisa alguma.

De modo análogo, podemos dizer que temos as três características essenciais dos padrões convencionais de medida: propósito, propriedades materiais e escala. Nossos sistemas sensoriais e nossa maleabilidade comportamental (suportada pela plasticidade neural) são as propriedades materiais que nos permitem medir o mundo. Somos "calibrados" para medir cores, objetos, sequências numéricas, etc. Os juízos de semelhança normativa funcionam como as escalas que estão gravadas em nós para o propósito de medir vários aspectos do mundo. Em virtude da aquisição de tais juízos, medimos o mundo instintivamente para o que é óbvio e para o que está isento de dúvida ${ }^{32}$.

A diferença mais significante entre a barra de um metro e as nossas próprias preocupações é o propósito destes padrões. O uso da barra de um metro é uma ação deliberada, enquanto reconhecer cores e objetos não envolve um uso deliberado de nós mesmos enquanto instrumentos ${ }^{33}$. Simplesmente vemos as cores. Não usamos nossos corpos para este propósito. O sucesso em realizar medições exige que todos alcancem as mesmas medidas: onde um sujeito $\mathrm{S}$ julga $\mathrm{x}$ como algo vermelho é preciso que os demais usuários concordem com este julgamento. Este aspecto da sociabilidade do padrão é a rigidez empírica exigida para realizar medições. Os teóricos da comunidade no que diz respeito ao que é seguir uma regra estão errados

32 WILLIAMS, M. Blind Obedience. New York: Oxford University Press, 2014. p. 3.

${ }^{33}$ WITTGENSTEIN, L. Philosophical Investigations. New York: Blackwell, 2001, §104. 


\section{Dossiê Naturalismo, Dissertatio - Volume Suplementar 02 | UFPel [2015]}

justamente neste aspecto, pois “Isto é vermelho" não significa necessariamente que "Os membros da comunidade chamam isto de vermelho". Como ressalta Williams, tomar como critério o fato de que "Os membros da comunidade chamam isto de vermelho" seria o mesmo que tomar a mesa como a medida da régua, e então não estaríamos mais medindo em termos de "metros" mas sim em termos de "mesas"34.

A rigidez da conformidade intersubjetiva sobre o que é um metropadrão é a própria rigidez da causação. As gravações na barra de metal são os resultados das causas operando na superfície do metal. A fixidez das gravações é tão importante quanto a rigidez da própria barra. Analogamente, os “juízos sobre o que é seguir de um mesmo modo" (the sameness judgements) que são constitutivos da escala e da conformidade em nossos julgamentos, são as duas formas de rigidez requeridas para nós (as quais refletem nossa situação causal no mundo). Assim, a sociabilidade intersubjetiva diz respeito a uma dimensão dessa rigidez que é necessária para estarmos aptos a julgar o mundo. Segundo Williams, as maneiras pelas quais estamos causalmente incorporados no mundo fornecem o material para as nossas práticas normativas, mas não podemos reduzir a normatividade de nossas práticas aos eventos causais além da própria rigidez da barra de metal que constitui o "um metro" de comprimento.

O comunitarismo ${ }^{35}$ e o behaviorismo clássico colocam os seres humanos como um todo na posição do aprendiz: vulnerável e aberto a verificação constante. A perspectiva intelectualista (cognitivista) sobre a aprendizagem da primeira linguagem natural coloca os seres humanos como um todo na posição do usuário competente da linguagem. Qualquer uma

${ }^{34}$ WILLIAMS, M. Normative Naturalism. International Journal of Philosophical Studies. № 18 (3), 2011. pp. 370-75.

${ }_{35}$ Refiro-me especificamente à solução cética de Kripke apresentada em "Wittgenstein on Rules and the Private Language". 
dessas duas maneiras exclusivas de compreender nossa situação no mundo acaba por obliterar necessariamente os papéis cruciais desempenhados pelo que Wittgenstein chamou de "pano de fundo" 36 , e isso nos leva ou a uma imagem fortemente behaviorista ou uma imagem fortemente intelectualista.

O processo de aquisição da linguagem natural é, portanto, um processo de enculturação dentro de práticas sociais, práticas que implementam as normas para "julgar" a realidade e que nos permitem realizar movimentos dentro dos jogos de linguagem. O processo de aprendizagem não se dá em um contexto epistêmico, mas sim um contexto de calibração e de ajuste de normas.

\footnotetext{
Ora, imaginemos que a criança seja um gênio e descubra por si própria um nome para a sensação! - Mas então, é claro, não poderia fazer-se entender com esta palavra. - Assim, pois, ela compreende este nome, mas não pode ensinar seu significado a ninguém? - Mas o que significa o fato de "ter denominado sua dor"? Como fez para denominar a dor?! E, seja o que for que tenha feito, que espécie de finalidade tem? Quando se diz: "Ele deu um nome à sensação", esquece-se o fato de que já deve haver muita coisa preparada na linguagem, para que o simples denominar tenha significação. (PI \$257)
}

O que Wittgenstein está mostrando através de seu diagnóstico sobre as posições intelectualistas é justamente que o "treinamento ostensivo" é uma prática de transmissão de habilidades que é necessariamente anterior ao processo intelectualizado de nomear, ou seja, que é anterior a prática de "definir ostensivamente". Não há dúvidas de que a linguagem natural é uma

36 John Searle também ressalta a importância do termo "background" em seu "Consciência e Linguagem", obra em que concorda explicitamente com a posição defendida aqui: "O fato de considerarmos que certos atos constituem a aplicação correta de uma regra e outros não; o fato de considerarmos que certos atos constituem um uso correto da adição e outros não, todos são simplesmente fatos de nossa conduta, fatos referentes ao modo como fomos criados e educados. (...) 0 que fixa a interpretação na prática efetiva, na vida real, é aquilo que chamei em outro lugar de "background"'. Ver: SEARLE, J. Consciência e Linguagem. São Paulo: Martins Fontes, 2010, p. 439. 


\section{Dossiê Naturalismo, Dissertatio - Volume Suplementar 02 | UFPel [2015]}

atividade adquirida, mas para isso é necessário adquirir antes as habilidades semânticas e cognitivas para compreender e seguir as regras socialmente transmitidas. Sem o desenvolvimento de tais habilidades não é possível adquirir uma linguagem natural.

As linguagens naturais geralmente exigem de seus usuários habilidades bastante específicas. Um estudo empírico realizado por Lera Boroditsky, da Universidade de Stanford, explorou o fato de que falantes nativos do inglês e falantes nativos do mandarim possuem diferentes modos de descrever o tempo. Boroditsky demonstrou que as habilidades exigidas por diferentes linguagens naturais possuem uma implicação direta nos modos de descrever a realidade. Seu experimento revelou que os falantes nativos do inglês em geral descrevem a passagem do tempo horizontalmente ("bons tempos à nossa frente", "muito tempo atrás", etc.). Em contraste, os falantes nativos do mandarim costumam descrever a passagem do tempo de modo vertical, utilizando-se de expressões como "acima" e "abaixo" para falar sobre os meses anteriores ou posteriores ${ }^{37}$.

Em outro estudo realizado recentemente, Boroditsky descreve o caso de uma menina de cinco anos de idade em Pormpuraaw (uma pequena comunidade aborígene na parte ocidental de Cape York no norte da Austrália) que é capaz de apontar imediatamente para o norte com precisão e sem hesitação, enquanto que muitos renomados cientistas não consegue fazê-lo ${ }^{38}$. A “diferença cognitiva” é explicada em termos do modo como uma linguagem natural molda o pensamento, pois a linguagem dos nativos de Pormpuraaw não possui pontos cardeais relativos, mas apenas absolutos (norte, sul, leste e oeste) e grande parte das expressões utilizadas revelam necessariamente a

${ }_{37}$ BORODITSKY, L. Does Language Shape Thought? Mandarin and English Speakers' Conceptions of Time. Cognitive Psychology, vol. 43, no. 1, pp. 1-22, Aug. 2001.

38 BORODITSKY, L. How Language Shape Thought? The Languages We Speak Affect our Perceptions of the World. Scienfic American, 2011. 
localização dos objetos descritos. Isso faz com que a linguagem natural da tribo aborígene exija mais fortemente de seus usuários a habilidade cognitiva de precisar a localização espacial de suas descrições.

As diferentes habilidades ficam mais evidentes quando observamos os diferentes modos de descrever um mesmo fato em diferentes linguagens naturais. Para utilizar um exemplo baseado na pesquisa de Boroditisky, suponha que S queira comunicar que viu sua tia na Rua 42. Se S é um falante nativo do mian em Papua Nova Guiné, então o verbo utilizado deverá revelar se o evento ocorre no presente, se ocorreu no passado recente ou no passado distante. Se S é um falante nativo do bahasa indonesiano, então o verbo utilizado para realizar a descrição não revelará se o evento já aconteceu ou se ainda está por acontecer. Se S é um falante nativo do russo, então ao realizar a descrição ele deverá revelar o seu gênero. Se S é um falante nativo do mandarim, então ele terá que especificar se sua tia é materna ou paterna (se ela está relacionada com ele pelo sangue ou pelo casamento), pois existem muitas palavras diferentes para todos estes tipos de relacionamentos. Se S é um falante nativo do pirahã (uma língua falada na Amazônia) ele não poderia dizer "42" pois não existem palavras para números exatos em pirahã, mas apenas números relativos (muitos, poucos, algum, nenhum).

\section{Considerações Finais}

As evidências apresentadas em anos recentes para sustentar a tese de Boroditsky além de desafiar a tese da universalidade da linguagem também abrem novas perspectivas sobre a origem do conhecimento e a construção da realidade. $O$ fato de que diferentes linguagens naturais exijam habilidades específicas de seus usuários também corrobora a tese de que tais habilidades sejam adquiridas através do "treinamento ostensivo" no processo de 


\section{Dossiê Naturalismo, Dissertatio - Volume Suplementar 02 | UFPel [2015]}

enculturação. Tais habilidades só são adquiridas em virtude de nossas propriedades materiais (percepção sensorial, plasticidade neural, etc.), as quais são susceptíveis à calibração. Portanto, as propriedades materiais são condições necessárias para a aquisição da linguagem natural, ainda que não sejam condições suficientes. Os modos de vida, ou mesmo os padrões sociais compartilhados, são os elementos complementares para o aprendizado de uma linguagem natural.

A distinção entre o "treinamento ostensivo" e a "definição ostensiva" é fundamental para explicar o processo de aquisição de uma linguagem natural, pois torna evidente que as habilidades requeridas pela linguagem natural são transmitidas através de um elemento não-semântico ou mesmo pré-linguístico. Se minhas considerações estiverem corretas, então o apriorismo e o inatismo cometem o mesmo erro: confundem o "treinamento ostensivo", enquanto um processo não-intelectualizado de transmissão de habilidades, com o processo altamente intelectualizado de nomear ou definir ostensivamente, um estágio do desenvolvimento da linguagem que notadamente só pode funcionar na medida em que as habilidades semânticas e cognitivas já tenham sido adquiridas e desenvolvidas.

A noção de "treinamento ostensivo" está intimamente relacionada com nossos padrões convencionais de atividade mais básicos. O treinamento ostensivo é, por natureza, independente de problemas de coordenação, de conformidades regulares e de pressupostos racionais. Uma característica importante deste modo de aprendizado é justamente o fato de que o aprendizado se dá por cópia direta de padrões convencionais de atividade que, ao invés racionalmente deliberados, são "cegamente reproduzidos". Isso quer significar que as habilidades cognitivas requeridas pelas linguagens naturais não dependem de qualquer mecanismo intrinsecamente superior para serem 
adquiridas ou desenvolvidas. A perspectiva naturalista de explicação do processo de aquisição primitiva de linguagem, defendida neste trabalho, tem a vantagem importante de harmonizar a determinação causal do treinamento ostensivo com a determinação lógica ou normativa do processo de enculturação, algo que não aparece explicitamente nas demais posições teóricas.

\section{REFERÊNCIAS}

BEAR, M.; CONNORS, B.; PARADISO, M. Neurociências: Desvendando o Sistema Nervoso. $3^{\circ}$ Edição. Porto Alegre: Artmed, 2010.

BORODITSKY, L. Does Language Shape Thought? Mandarin and English Speakers' Conceptions of Time. Cognitive Psychology, vol. 43, no. 1, pp. 1-22, Aug. 2001. BORODITSKY, L. How Language Shape Thought? The Languages We Speak. Affect our Perceptions of the World. Scienfic American, 2011.

COWIE, F. Innateness and Language. Stanford Enciclopedia of Philosophy, 2008. ENGELLAND, C. Ostension: Word Learning and the Embodied Mind. Massachusetts: MIT, 2015.

FODOR, J. The Language of Thought. New York: Thomas Y. Crowell Company, 1975.

HORWICH, P. Meaning. Oxford: Oxford University Press, 1996. - Naturalism, Deflationism and the Relative Priority of Language and Metaphysics. In: Price, H. Expressivism, Pragmatism and Representationalism. New York: Cambridge University Press, 2013.

KUHL, P.K. Learning and Representation in Speech and Language. Current Opinion in Neurobiology, 4: 812-822, 1994.

KRIPKE, S. Wittgenstein on Rules and Private Language. Cambridge: Harvard 


\section{$\underline{\text { Dossiê Naturalismo, Dissertatio - Volume Suplementar 02 }}$ UFPel [2015]}

University Press, 1982.

LEWONTIN, R. The Evolution of Cognition: Questions we will Never Answer, In R. Sternberg and D. Scarborough (eds.). An Invitation to Cognitive Science. Cambridge: MIT Press, 1998.

RYLE, G. The Concept of Mind. New York: Routledge, 1949

SEARLE, J. Consciência e Linguagem. São Paulo: Martins Fontes, 2010.

SKINNER, B. F. Verbal Behavior. New York: Appleton-Century-Crofts, 1957.

WILLIAMS, M. Blind Obedience. New York: Oxford University Press, 2014. . Normative Naturalism. International Journal of Philosophical Studies.

No 18 (3): pp. 355-375, 2011.

WINOKUR, S. A primer of verbal behavior: an operant view. Englewood Cliffs: Prentice-Hall, 1976.

WITTGENSTEIN, L. Philosophical Investigations. New York: Blackwell, 2001. 